
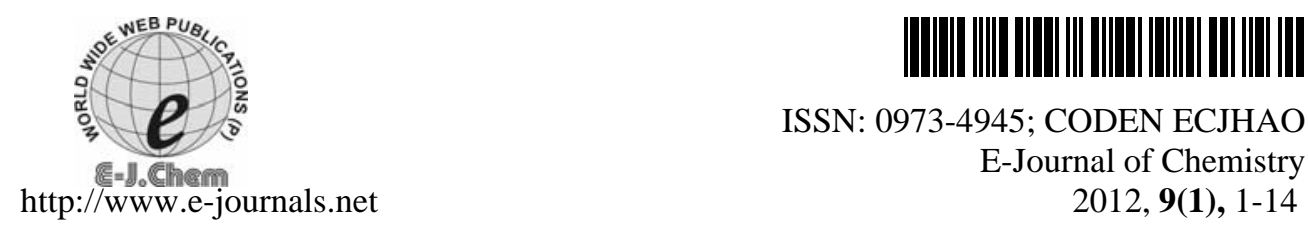

ISSN: 0973-4945; CODEN ECJHAO

E-Journal of Chemistry

2012, 9(1), 1-14

\title{
A Study of Interaction of Methyl Orange with Some Polycations
}

\author{
R. NANDINI and B. VISHALAKSHI* \\ Department of Post-Graduate studies and Research in Chemistry \\ Mangalore University, Mangalagangotri 574199 (DK), India \\ vishalakshi2009@yahoo.com
}

Received 29 June 2010; Accepted 2 September 2010

\begin{abstract}
The interaction between an anionic dye methyl orange and three poly cations namely, poly ( $N$-methy-4-vinylpyridinium iodide) (PM4VPI), poly (vinylbenzyltriphenyl phosphonium chloride) (PVBTPPC) and poly ( $N$-methy-4vinylpyridinium iodide) (PM2VPI) has been investigated by spectrophotometric method. The polymers were observed to induce metachromasy in the dye as evidenced from the considerable blue shift in the absorption maxima of the dye. The interaction constant and thermodynamic parameters of interaction have been determined by absorbance measurements at the metachromatic band. The effect of additives such as ionic salts, alcohols, urea and polyelectrolytes on the reversal of metachromasy has been studied and used to determine the stability of the metachromatic complex and to understand the nature of binding.
\end{abstract}

Keywords: Methyl Orange, Polycations, Metachromasy, Stoichiometry, Thermodynamic parameters

\section{Introduction}

Metachromasy due to binding with proteins is generally weak but occurs with acidic dyes like, Methyl Orange. The addition of a suitable organic acid to a solution of methyl orange azosulfathiazole protein complex causes reversal of metachromasy which is considered due to the fact that the organic amine displaces the dye anion from the binding sites on the protein molecules. Thus it seems likely that the competitive binding ability of an organic acid on acidic dye should be a measure of the strength of its binding with the protein molecule and in fact that has been confirmed by equilibrium dye binding studies ${ }^{1}$.

The interaction of methyl orange, ethyl orange and butyl orange with poly ( $L$-ornithine, poly- $L$-lysine) and trimethyldodecylammonium chloride and with two proteins, bovine serum albumin and lysozyme has been studied ${ }^{2}$. The results are explained on the basis of conformational change of bound dye molecule. The interaction of methyl orange with bovine serum albumin and with lysozyme could mainly results in a partial solubilisation of the dye in the hydrophobic region of the proteins. 
The binding of methyl orange, ethyl orange, propyl orange by poly (vinyl pyrrolidone), has been examined ${ }^{3}$ by equilibrium dialysis method, in the temperature range from $5-35{ }^{0} \mathrm{C}$ and $60-90{ }^{\circ} \mathrm{C}$. At lower temperature the free energy and enthalpy changes are all negative and the entropy changes are positive. The above facts are explained in terms of hydrophobic interaction between the hydrocarbon portion of the dye molecule and the non-polar part of macromolecule. At higher temperatures the complex formation between the dye and the macromolecule $e^{4}$ is associated with an exothermic enthalpy change and the binding was mainly enthalpy controlled. All these observations in the higher temperature range can be explained as a result of disruption of water structure in the binding environment and hence a decrease in hydrophobic bond formation between the dye and the polymer.

The binding of methyl orange, ethyl orange, butyl orange and pentyl orange with polyion complexes of sodium poly methacrylate and dimethyldiallylammonium chloride and sulfurdioxide, diethyldiallylammoniumchloride with sulfur dioxide, methylbenzyldiallylammonium chloride and sulfur dioxide has been studied ${ }^{5}$ in aqueous solution. The strength of binding is enhanced by increase in the hydrophobicity of the polyion complex and the small co solute. The effect of $\mathrm{KCl}$ and urea on binding has been studied. The significance of electrostatic interactions accompanying the binding is discussed.

The interaction of methyl orange, ethyl orange, propyl orange and butyl orange with a polyion complex consisting of equimolar sodium polymethacrylate and piperidinium cationic polymer was measured ${ }^{6}$ in ethylene glycol at 25,30 and $35{ }^{0} \mathrm{C}$. The effects of aqueous and non-aqueous media on the binding of the dye by the polymer matrix was compared. The authors suggested that electrostatic forces are principal contributors to the copolymer complex formation. The binding behavior observed in the non-aqueous solvent is accounted in terms of disappearance of hydrophobic interaction between the dye and the polymer and an increase in electrostatic attraction between the anionic molecule and the positively charged sites on the polyion complex.

The interaction of poly (2-diethylaminoethyl methacrylate) with methyl orange and its homologs in aqueous solution and the temperature dependence of the complex formation have been examined ${ }^{7}$ in detail by the measurements of transmittance and specific conductance for the systems. The thermodynamic parameters of interaction $\Delta \mathrm{G}, \Delta \mathrm{H}$ and $\Delta \mathrm{S}$ suggested that for dye-PDEAEMA complex formation,the hydrophobic interaction is predominant at low temperatures but electrostatic interaction becomes important as the temperature increases.

The interaction of $\mathrm{N}$-acylated, both aliphatic and aromatic chitosan gels was investigated by DSC technique ${ }^{8}$. The interaction between these hydrogels with methyl orange and butyl orange has been investigated and the contribution of the electrostatic and hydrophobic and hydrogen bonding interaction on the sorption behavior was discussed.The predominant contribution of the hydrophobic interaction in the systems of butyl orange/ $\mathrm{N}$-octanoyl chitosan gels has been made clear by means of temperature dependence of sorption. The interaction of methyl orange with aliphatic ionones has been reported ${ }^{9}$ in literature. The metachromatic effect is found to be dependent on the nature of the hydrophobic portion of the ionone.

Prompted by the above reports, it has been attempted to study the interaction between the three synthetic polycations, namely, poly ( $N$-methyl-4-vinylpyridinium iodide), (PM4VPI), Poly (vinylbenzyltriphenylphosphonium chloride) (PVBTPPC) and poly ( $N$-methyl2-vinylpyridinium iodide (PM2VPI) with anionic dye, methyl orange. A comparative account of stoichiometry of complex formation, stability of complexes formed and thermodynamics of interaction are reported. 


\section{Experimental}

Methyl orange (MO) was obtained from (Merck, Mumbai) and used as received. Methanol $(\mathrm{MeOH})$, ethanol $(\mathrm{EtOH})$ and 2-propanol $(\mathrm{PrOH})$ (Merck, India) were distilled before use. Urea, sodium chloride ( $\mathrm{NaCl}$ ) (Merck, India), were used as received.sodium laurylsulphate(SLS) (Lobachemie, India) were used as received.

\section{Apparatus}

All the absorbance measurements were recorded using a Shimadzu UV-2550 spectrophotometer.

Structure and absorption characteristics of methyl orange

Methyl Orange is an anionic dye with the following structure:<smiles>CN(C)c1ccc(N=Nc2ccc(S(N)(=O)=O)cc2)cc1</smiles>

The absorption spectra of methyl orange is shown below

\section{Results and Discussion}

\section{Effect of polymer concentration on metachromasy}

The absorption spectrum of methyl orange shows a peak at $464 \mathrm{~nm}$ (Figure 1). This band is assigned to the respective monomeric dye species in the concentration range studied. The intensity of monomer bands were found to decrease progressively upon addition of increasing amounts of polymer solution and the absorption maxima shifts to $378 \mathrm{~nm}$ in case of MO-PM4VPI (Figure 2), $426 \mathrm{~nm}$ in case of MO-PVBTPPC (Figure 3) and $387 \mathrm{~nm}$ in case of MO-PM2VPI (Figure 4). The blue shifted bands are attributed to the stacking of the dye molecules on the polymer backbone and this reflects high degree of cooperativity in binding ${ }^{10}$. Appearance of multiple banded spectra proposed that the polymer might have a random coil structure in solution. At higher concentration of the polymer a single banded spectrum was observed due to possible change in conformation from random coil to helical form ${ }^{11}$. The absorption spectra of methyl orange has been studied in the concentration range $4 \times 10^{-5} \mathrm{M}$ to $6 \times 10^{-5} \mathrm{M}$. The dye shows monomeric band $(464 \mathrm{~nm})$ in the concentration range studied.

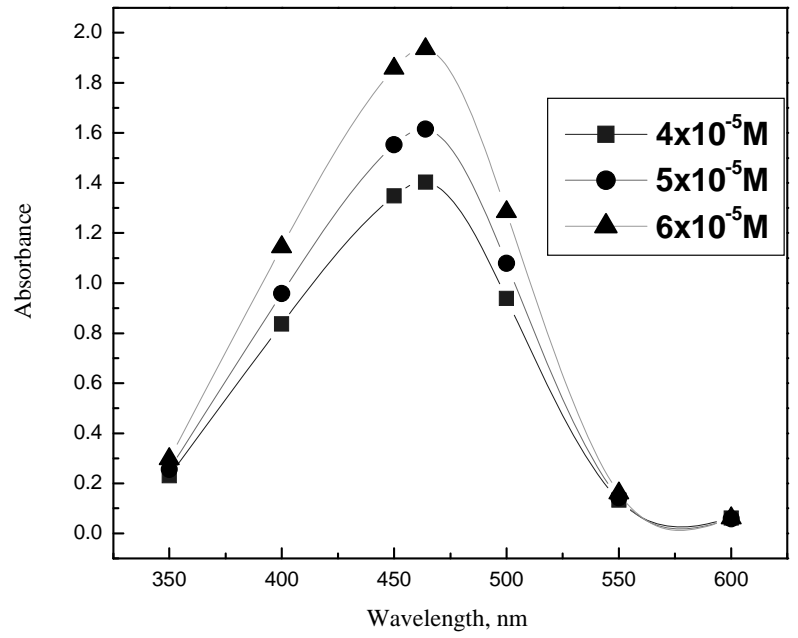

Figure 1. Absorption spectra of dye, MO at various concentrations 


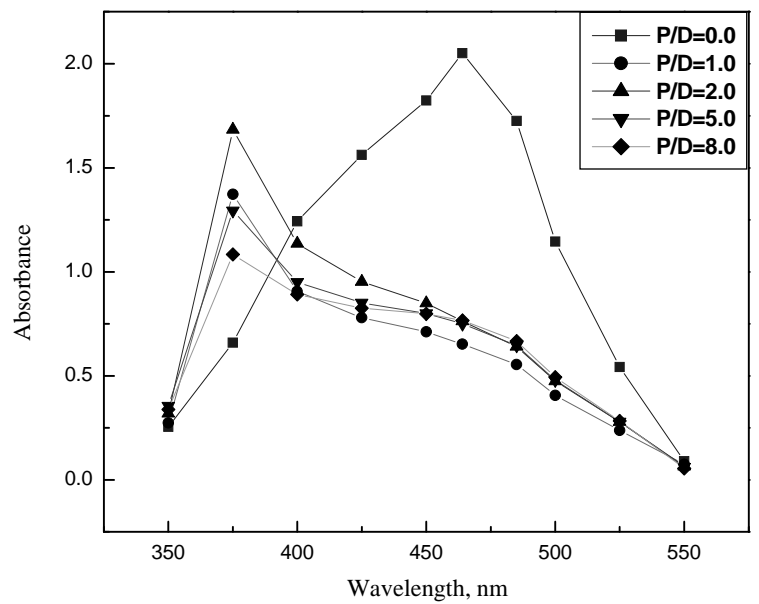

Figure 2. Absorption spectrum of MO- PM4VPI system at various P/D ratios

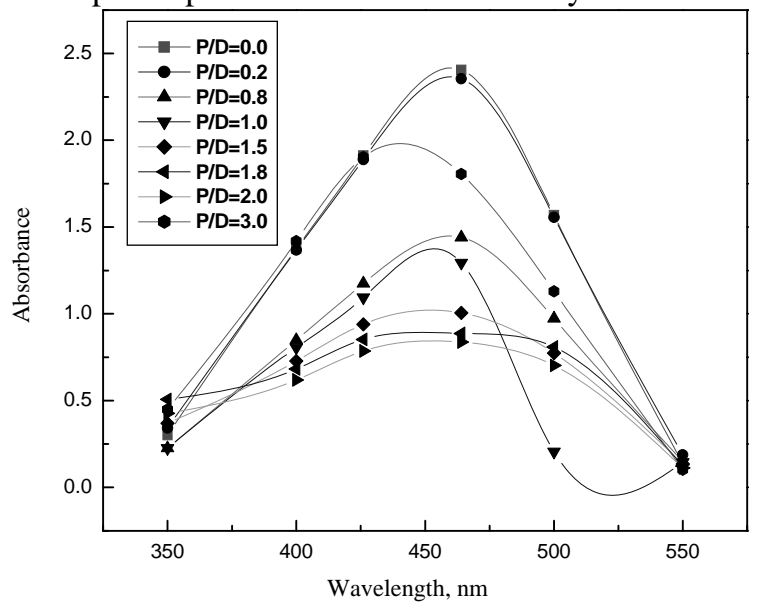

Figure 3. Absorption spectrum of MO- PVBTPPC system at various P/D ratios

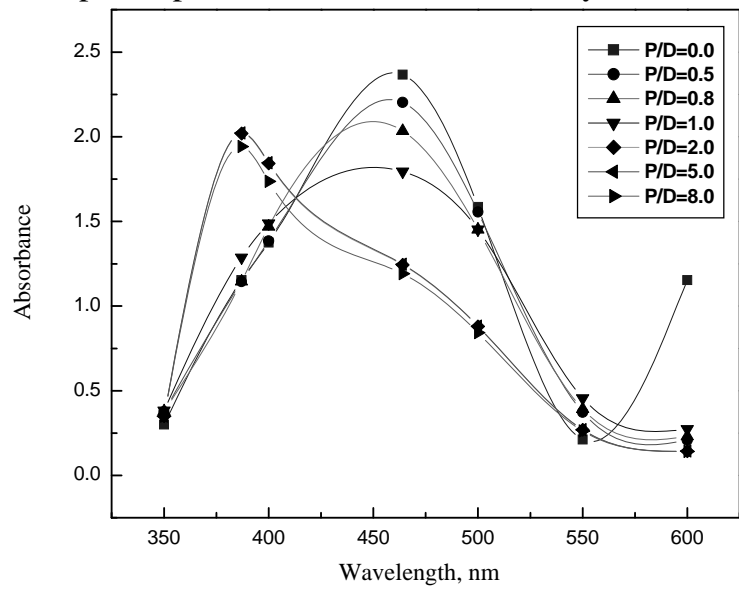

Figure 4. Absorption spectrum of MO- PM2VPI system at various P/D ratios 


\section{Determination of stoichiometry}

To determine the stoichiometry of the polymer-dye complex, a plot of $A_{464} / A_{378}$ versus the polymer/dye ratio was made for MO- PM4VPI system. A similar procedure was adopted for other systems also. In case of MO-PVBTPPC system the stoichiometry is 1:1. A 1:1 stoichiometry indicates that the binding is at adjacent cationic sites. This stoichiometry indicates that every potential cationic site of the polymer was associated with the dye anion and aggregation of such dye molecules was expected to lead to the formation of a card pack stacking of the individual monomers on the surface of the polycation so that the allowed transition produces a blue-shifted metachromasy ${ }^{12}$. The results were in good agreement with the reported values for interaction of similar dyes with polyions ${ }^{13}$. In case of MO- PM4VPI and MO-PM2VPI systems the stoichiometry is found to be 2:1.This indicates that there is lesser overcrowding and more aggregation of the bound dyes on the polymer chain. Similar results were reported in case of binding of pinacyanol chloride on poly (methacrylic acid) and poly (styrene sulfonate) systems ${ }^{14}$. The result is shown in (Figure 5).

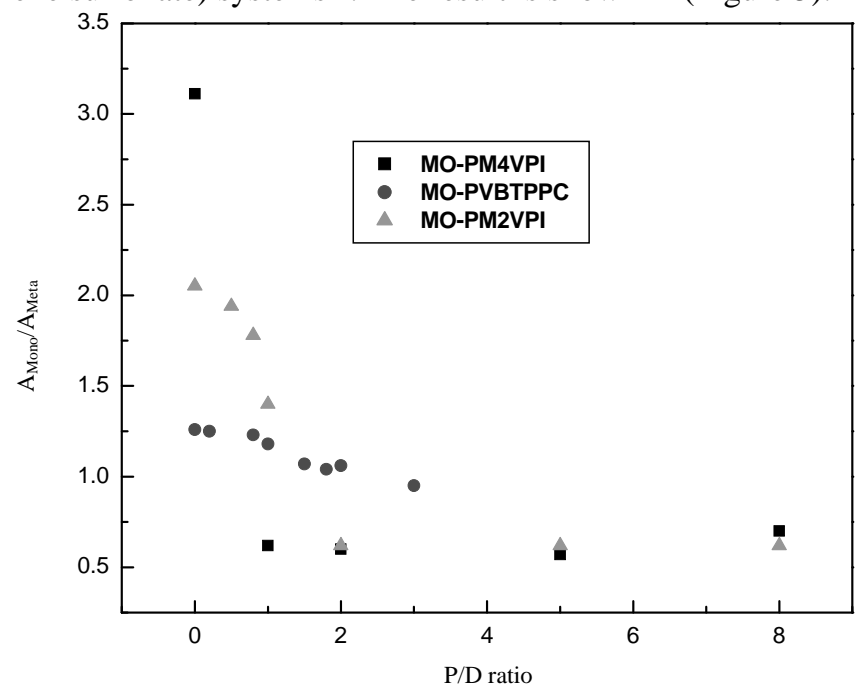

Figure 5. Stoichiometry of MO- polycation complexes

\section{Reversal of metachromasy using alcohols and urea}

The metachromatic effect is presumably due to the association of the dye ion with the polyelectrolyte resulting in extended interaction. The destruction of metachromasy by alcohol and urea is attributed to the involvement of hydrophobic bond in the induction of metachromasy. The fact that urea weakens hydrophobic bonding has already been established. This has ${ }^{15-17}$ been ascribed for breaking up of hydrogen bonds in water and thus destroying the icebergs which presumably are associated with fairly large scale cooperative structures stabilized by water-water hydrogen bonding. Thus urea increases the surface tension of water slightly and reduces the dielectric constant appreciably. The efficiency of alcohols in disrupting metachromasy was found to be in the order methanol<ethanol< 2-propanol indicating that reversal becomes quicker with increasing hydrophobic character of the alcohols. The above facts are further established in the present system by measuring the absorbance at $464 \mathrm{~nm}$ and $378 \mathrm{~nm}$ in case of MO-PM4VPI and a plot of $\mathrm{A}_{378} / \mathrm{A}_{464}$ was made to explain the result (Figure 6).Similar plots were made with urea also (Figure 7). In case of 
MO-PM4VPI 60\% methanol, 50\% ethanol and 40\% 2-propanol were sufficient to reverse metachromasy. The concentration of urea to reverse metachromasy is $6 \mathrm{M}$ in case of MO-PM4VPI system. Similar reports are available in literature for reversal of metachromasy in anionic polyelectrolyte/cationic system by addition of alcohols or urea ${ }^{18-22}$. The reversal studies using alcohols and urea suggests the involvement of hydrophobic forces in polymer-dye interaction.

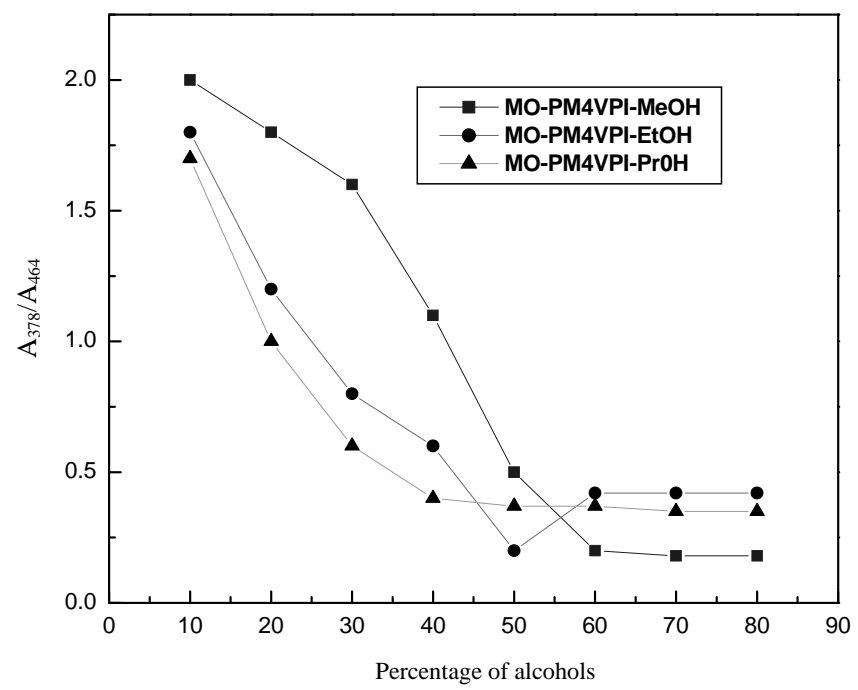

Figure 6. Reversal of metachromasy on addition of alcohols

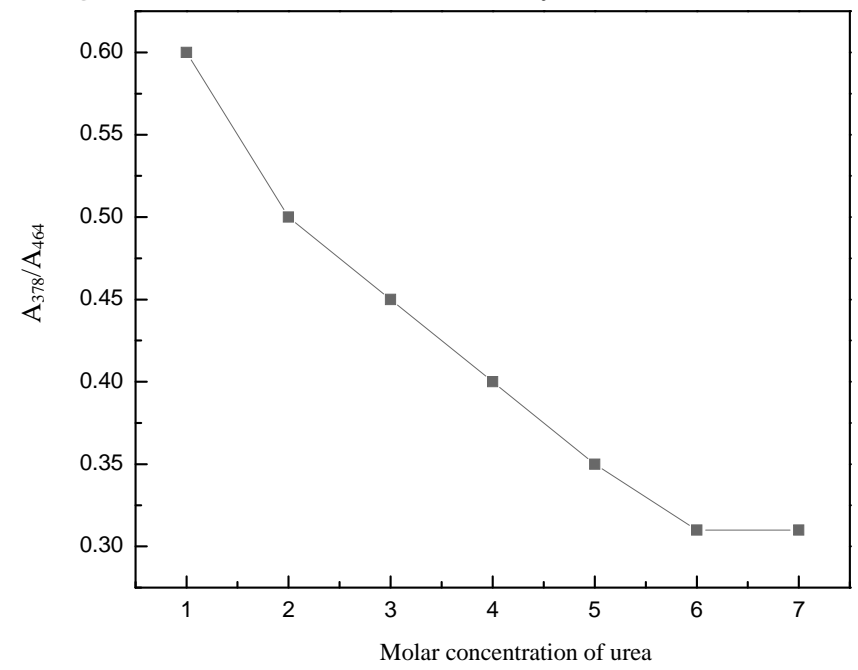

Figure7. Reversal of metachromasy on addition of urea

\section{Effect of electrolytes}

Tan et $a l^{23}$ have reported the disruption of metachromatic band with the variation of ionic strength. In aqueous solutions the charged polymer molecule will be in the extended conformation due to the repulsion between the charged groups. On adding the dye the conformation of the polycation changes to a compact coil owing to dye binding, resulting from 
electrostatic interaction thus giving rise to metachromatic band. In the present investigation sodium chloride of varied ionic strength were added to MO- PM4VPI and the absorbance's were measured in the range $350-700 \mathrm{~nm}$. The monomer band reappears at a concentration of $1 \times 10^{-4} \mathrm{M}$. These observations can be explained in terms of conformation of polymer. The result is shown in (Figure 8). Similar results were observed with sodium carboxymethylcellulose also (Figure 9).

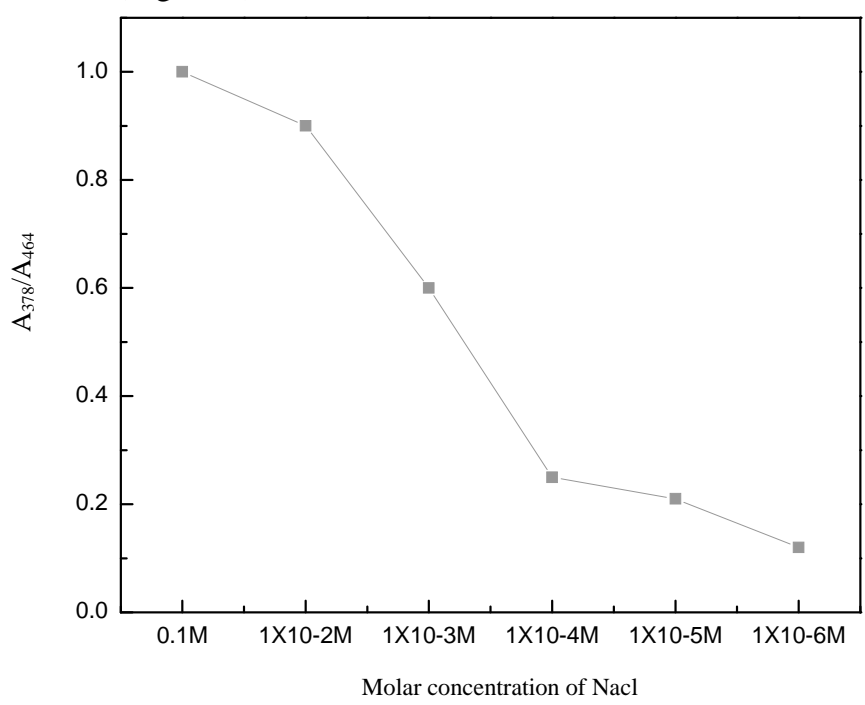

Figure 8. Reversal of metachromasy on addition of $\mathrm{NaCl}$

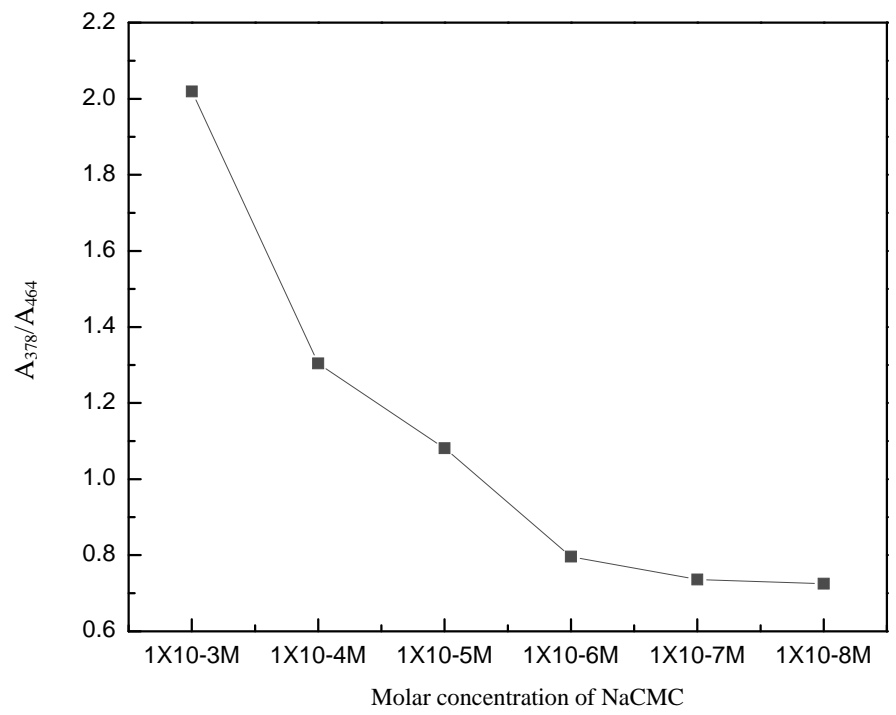

Figure 9. Reversal of metachromasy on addition of NaCMC

\section{Effect of surfactants}

The strength and nature of interaction between water soluble polyelectrolyte and oppositely charged surfactants depend on the characteristic features of both the polyelectrolyte and the 
surfactant. The charge density, flexibility of the polyelectrolyte and the hydrophobicity of the non-polar part and the bulkiness of the polar part also play a vital role in the case of polymer-surfactant interaction ${ }^{24}$. The molar concentrations of Sodium laurylsulphate needed to cause reversal was found to be $1 \times 10^{-4} \mathrm{M}$. The results agree with those reported earlier in literature ${ }^{25}$. Thus the surfactant molecules interacted with the polymer by replacing the anionic dye. The release of dye molecules from the dye-polymer complex in presence of surfactant revealed that surfactant interacted electrostatically ${ }^{26}$ with the cationic site of the polymer and thus the dye becomes free. The ease of reversal of metachromasy can be correlated with its chain length ${ }^{27}$. Thus the binding between oppositely charged polymer and the surfactant is primarily electrostatic force which is reinforced by hydrophobic forces. The result is given in (Figure 10).

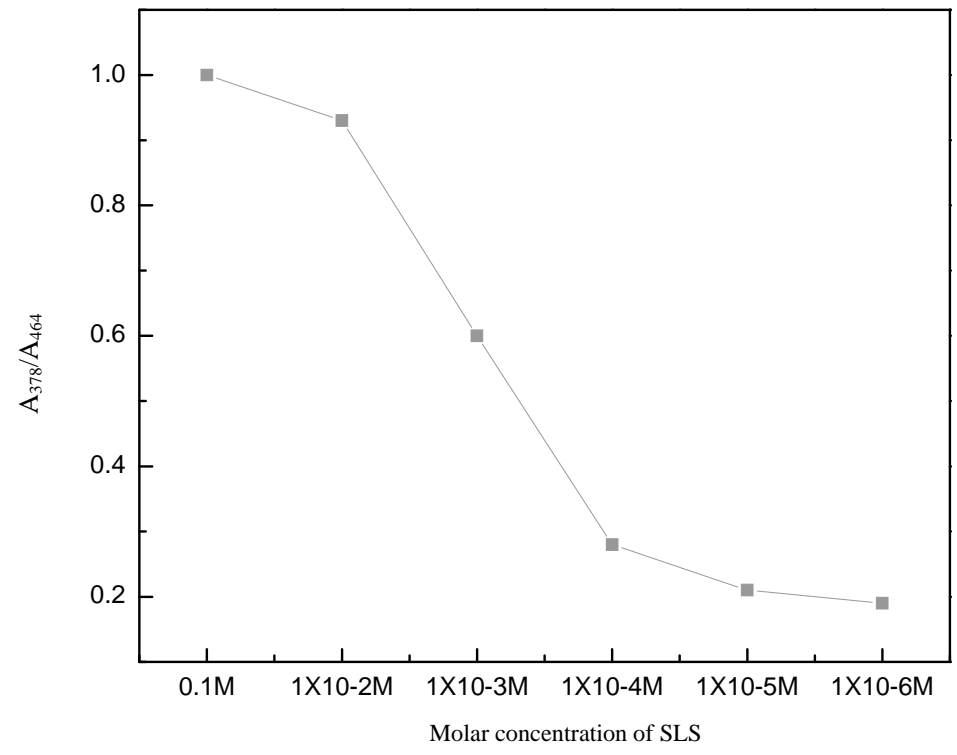

Figure 10. Reversal of metachromasy on addition of SLS

Reversal of metachromasy using above mentioned additives was studied with the other two polycations also and the results are tabulated in Table 1.

Table 1. A comparative account of reversal parameters

\begin{tabular}{ccccccc}
\hline System & \multicolumn{3}{c}{$\begin{array}{c}\text { Percentage of } \\
\text { alcohols }\end{array}$} & Urea & NaCl/NaCMC & SLS \\
\hline MO-PM4VPI & 60 & 50 & 40 & $6 \mathrm{M}$ & $1 \times 10^{-4} \mathrm{M} / 1 \times 10^{-6} \mathrm{M}$ & $1 \times 10^{-4} \mathrm{M}$ \\
MO-PVBTPPC & 40 & 30 & 25 & $5 \mathrm{M}$ & $1 \times 10^{-4} \mathrm{M} / 1 \times 10^{-5} \mathrm{M}$ & $1 \times 10^{-4} \mathrm{M}$ \\
MO-PM2VPI & 55 & 45 & 35 & $4.5 \mathrm{M}$ & $1 \times 10^{-4} \mathrm{M} / 1 \times 10^{-4} \mathrm{M}$ & $1 \times 10^{-4} \mathrm{M}$ \\
\hline
\end{tabular}

\section{Determination of interaction parameters}

The value of $K_{c}$ was obtained from the slope and intercept of the plot of $C_{D} C_{S} /\left(A-A_{O}\right) v s$. Cs using the expression $\mathrm{K}_{\mathrm{c}}=$ slope/ (intercept) $^{28}$ also the thermodynamic parameters of interaction $\Delta \mathrm{G}, \Delta \mathrm{H}$ and $\Delta \mathrm{S}$ were evaluated. 


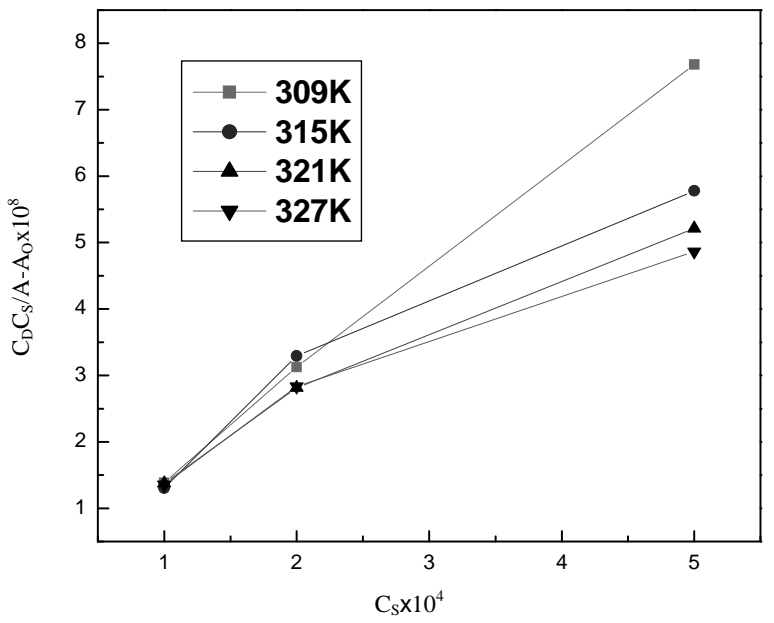

Figure 11. Plot of $C_{D} C_{S} /\left(A-A_{O}\right)$ vs. $C_{S}$ for MO-PM4VPI at different temperatures

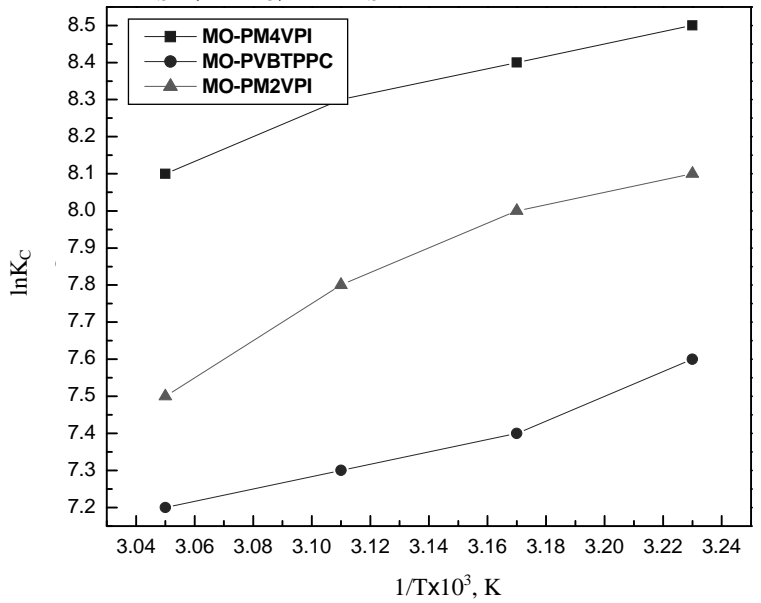

Figure 12. Van't Hoff plots for MO-polycation systems

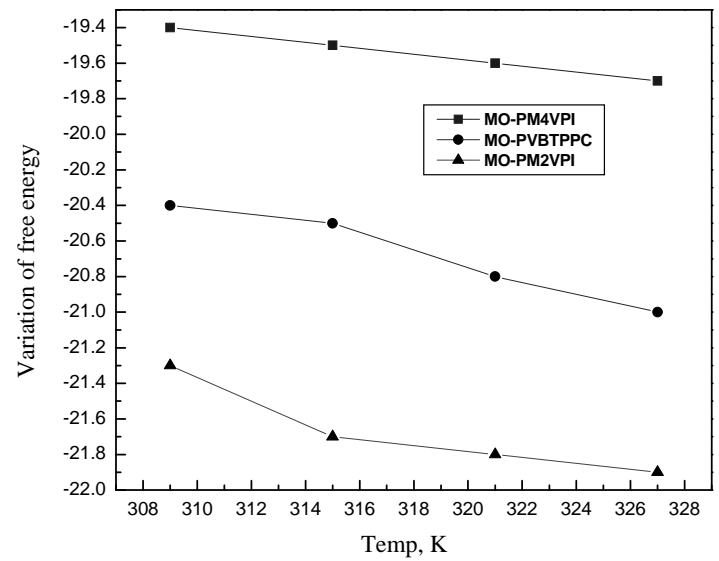

Figure 13. Free energy plots for MO-polycation systems 
From Table 2, it is seen that the $\mathrm{K}_{\mathrm{C}}$ obtained in case of MO-PM4VPI is highest and that of MO-PVBTPPC is lowest among the three systems studied, which could be due to the lower steric hindrance offered by methyl groups compared to triphenylphosphonium groups.The change in enthalpy and entropy of dye-polycation complex formation are in the order PVBTPPC > PM2VPI > PM4VPI.

Table 2. Thermodynamic parameters for MO-polycation systems

\begin{tabular}{|c|c|c|c|c|c|c|c|c|c|c|}
\hline \multirow{2}{*}{$\begin{array}{c}\text { Temp } \\
\text { (K) }\end{array}$} & \multicolumn{2}{|c|}{$\mathrm{K}_{\mathrm{C}}, \mathrm{dm}^{3} \mathrm{~mol}^{-1 \mathrm{a}}$} & \multicolumn{3}{|c|}{$\Delta \mathrm{G}, \mathrm{kJ}^{\mathrm{mol}} \mathrm{m}^{-1 \mathrm{~b}}$} & \multicolumn{2}{|c|}{$\Delta \mathrm{H}, \mathrm{kJ} \cdot \mathrm{mol}^{-1 \mathrm{c}}$} & \multicolumn{3}{|c|}{$\Delta \mathrm{S}, \mathrm{J} \cdot \mathrm{mol}^{-1} \mathrm{~K}^{-1 \mathrm{~d}}$} \\
\hline & I II & III & I & II & III & I II & III & I & II & III \\
\hline 309 & 48661954 & 3342 & -19.5 & -20.8 & $3-21.8$ & $-18.0-27$. & $7-20.1$ & -16.7 & -38.3 & -33.3 \\
\hline 315 & 43081666 & 3142 & -19.4 & -21.1 & $1-21.9$ & & & & & \\
\hline 321 & 42661585 & 2876 & -19.6 & -21.3 & $3-22.3$ & & & & & \\
\hline 327 & 31641331 & 1804 & -19.5 & -20.1 & -21.9 & & & & & \\
\hline
\end{tabular}

I MO-PM4VPI, II MO-PVBTPPC, III MO-PM2VPI

a) Calculated from Figure 11 according to Rose-Drago equation, b) Calculated from the thermodynamic equation $\left.\Delta G=-R T \ln K_{c}, c\right)$ Calculated graphically by plotting $\ln K_{c}$ against $1 / T$ according to Van't Hoff equation $\ln K_{c}=-\Delta H / R T+C$, d) Calculated from the thermodynamic expression $\Delta G=\Delta H-T \Delta S$.

IR analysis of complexes

In the IR spectra of $\mathrm{MO}$, the $-\mathrm{C}=\mathrm{C}$ - stretching was observed at $1599 \mathrm{~cm}^{-1}$, the $-\mathrm{S}=\mathrm{O}$ stretching was observed at $1119.5 \mathrm{~cm}^{-1}$, the-C=N stretching was observed at $1313.7 \mathrm{~cm}^{-1}$, $-\mathrm{N}-\mathrm{H}$ stretching was observed at $3209.1 \mathrm{~cm}^{-1}$. In the IR spectra of PM4VPI the aromatic $-\mathrm{C}-\mathrm{H}$ stretch was observed at $3080 \mathrm{~cm}^{-1}$, the $\mathrm{C}=\mathrm{C}$-stretching was observed at $1662.1 \mathrm{~cm}^{-1}$, $-\mathrm{C}-\mathrm{H}$ bending was observed at $802.4 \mathrm{~cm}^{-1}$, the $-\mathrm{C}-\mathrm{H}$ stretching was observed at $2893.1 \mathrm{~cm}^{-1}$ and the $-\mathrm{CH}_{3}$ vibrations was observed at $1442.5 \mathrm{~cm}^{-1}$. In the IR spectra of MO-PM4VPI complex, the aromatic $-\mathrm{C}-\mathrm{H}$ stretch was observed at $3040 \mathrm{~cm}^{-1}$, the $-\mathrm{C}=\mathrm{C}$-stretching was observed at $1629 \mathrm{~cm}^{-1}$, -C-H bending was observed at $892 \mathrm{~cm}^{-1}$, the $-\mathrm{C}-\mathrm{H}$ stretching was observed at $2935 \mathrm{~cm}^{-1}$ and the $-\mathrm{CH}_{3}$ vibrations was observed at $1437 \mathrm{~cm}^{-1}$ (Figure 14).

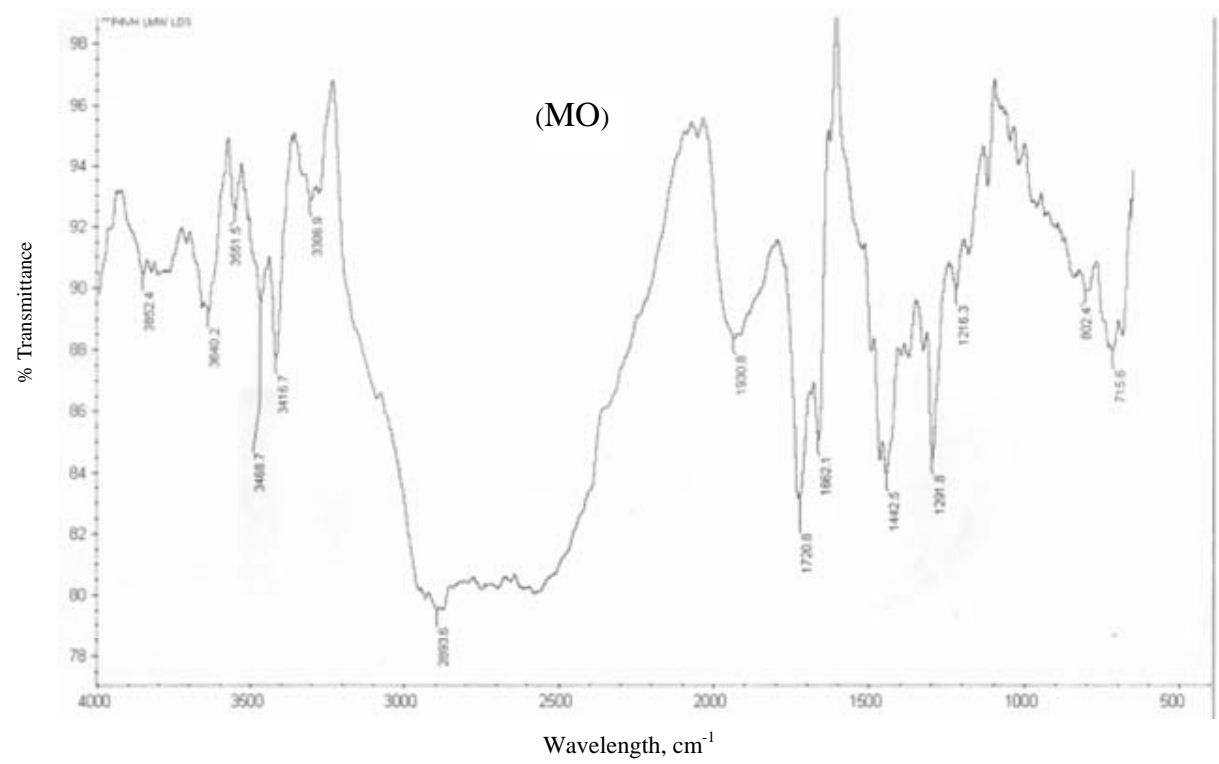



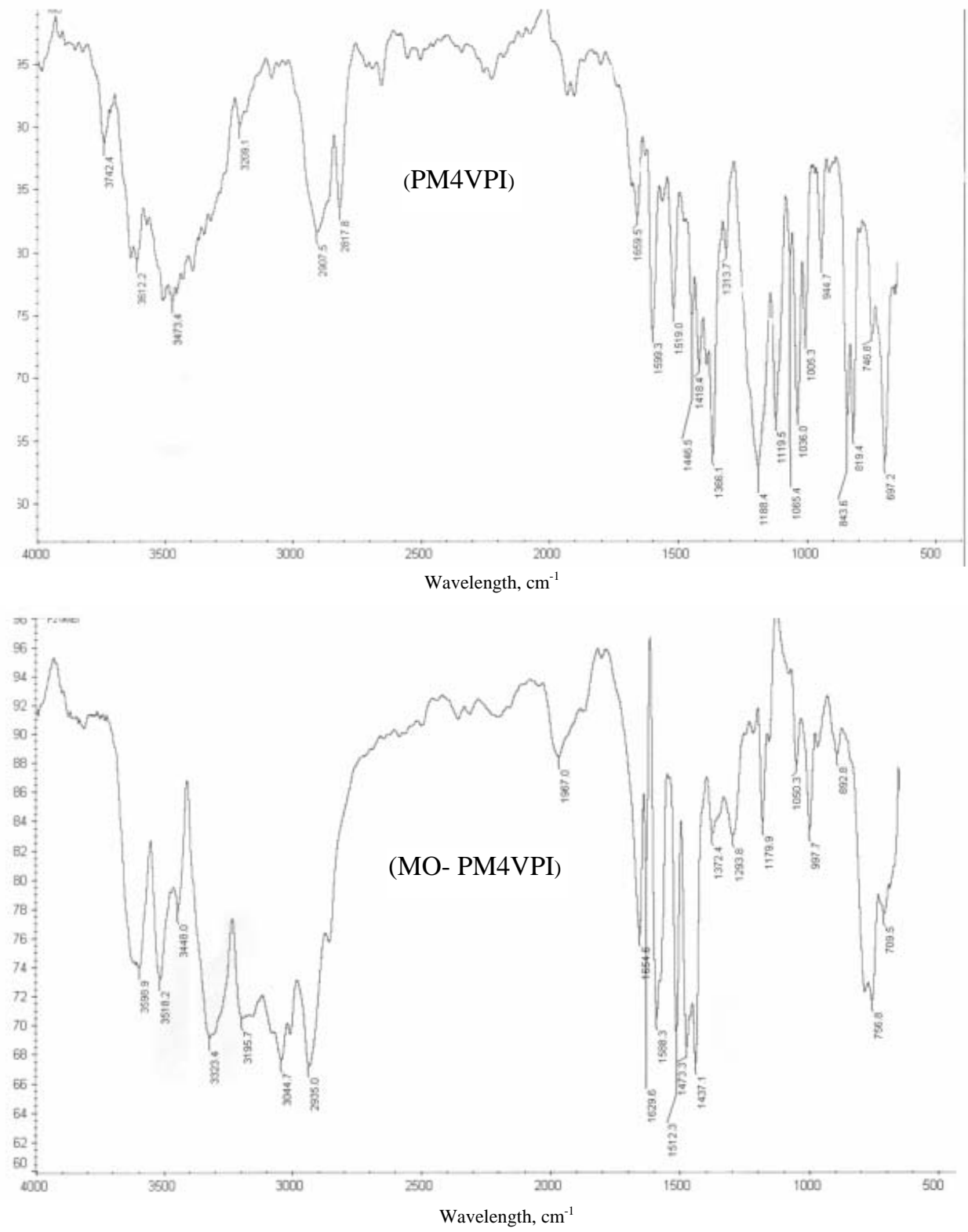

Figure 14. IR spectra of MO, PM4VPI and MO- PM4VPI complex

In the IR spectra of PVBTPPC, the -C-H stretching was observed at $2853.1 \mathrm{~cm}^{-1}$, the $-\mathrm{CH}_{3}$ band was observed at $1482 \mathrm{~cm}^{-1}$, the $-\mathrm{C}-\mathrm{H}$ bending peak was observed at $894.5 \mathrm{~cm}^{-1}$, the $-\mathrm{C}=\mathrm{C}$ - stretching was observed at $1659 \mathrm{~cm}^{-1}$ and the aromatic $-\mathrm{C}-\mathrm{H}$ stretching band was observed at $3052 \mathrm{~cm}^{-1}$.In the IR spectra of MO-PVBTPPC complex, the peak at $802.4 \mathrm{~cm}^{-1}$ corresponds to $\mathrm{C}-\mathrm{H}$ bending vibrations, the $-\mathrm{CH}_{3}$ group was observed at $1442 \mathrm{~cm}^{-1}$, the Ar-C-H stretch was observed at $2893 \mathrm{~cm}^{-1}$, the- $\mathrm{C}=\mathrm{C}-$ stretch was observed at $1662 \mathrm{~cm}^{-1}$ (Figure 15). 

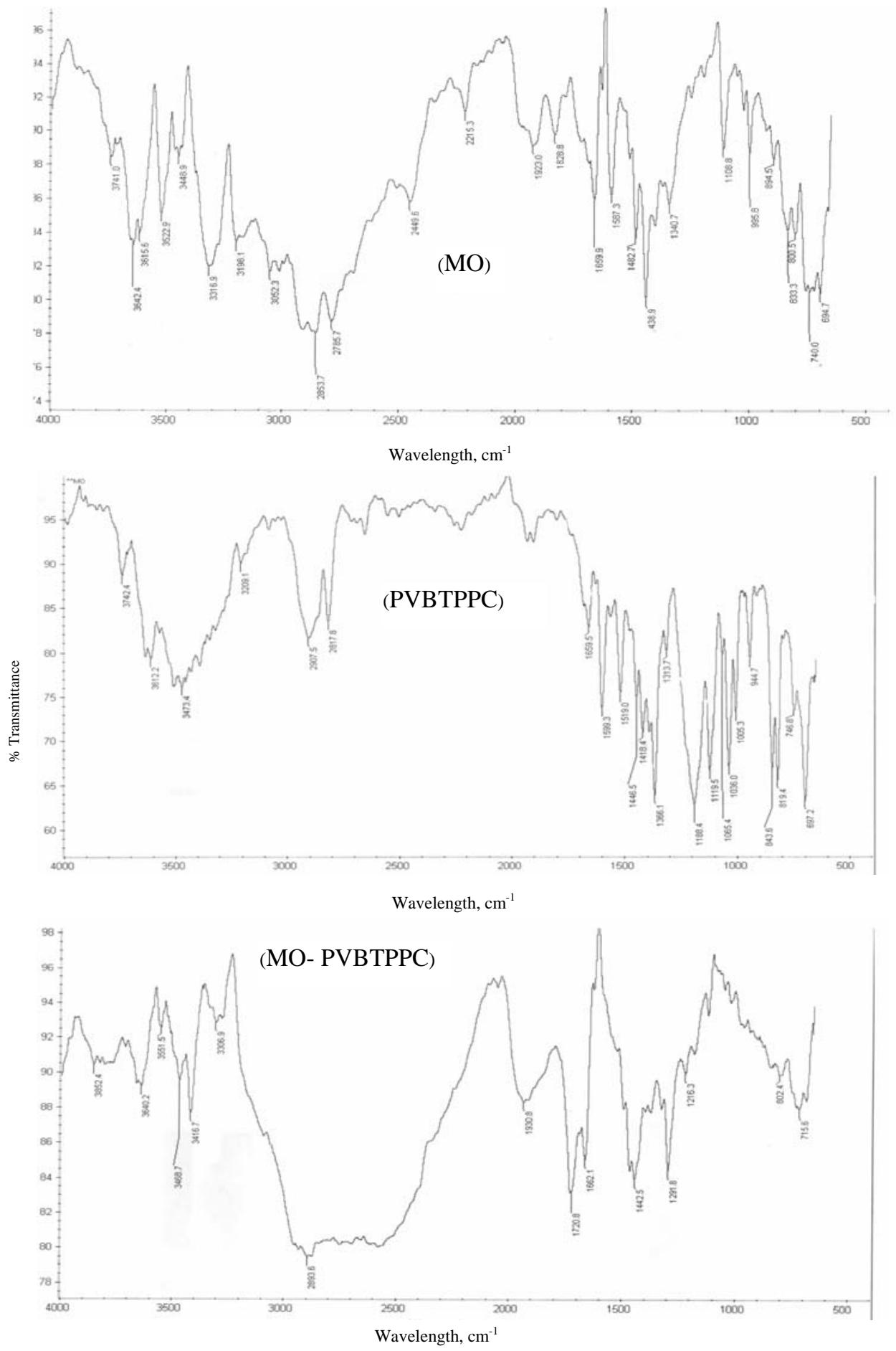

Figure 15. IR spectra of MO, PVBTPPC and MO- PVBTPPC complex 
In the IR spectra of PM2VPI, the aromatic $-\mathrm{C}-\mathrm{H}$ stretch was observed at $3040 \mathrm{~cm}^{-1}$, the $-\mathrm{C}=\mathrm{C}$ stretching was observed at $1629 \mathrm{~cm}^{-1}$, -C-H bending was observed at $892 \mathrm{~cm}^{-1}$, the $-\mathrm{C}-\mathrm{H}$ stretching was observed at $2935 \mathrm{~cm}^{-1}$ and the $-\mathrm{CH}_{3}$ vibrations was observed at $1437 \mathrm{~cm}^{-1}$. In the IR spectra of MO-PM2VPI the aromatic $-\mathrm{C}-\mathrm{H}$ stretch was observed at $3080 \mathrm{~cm}^{-1}$, the $-\mathrm{C}=\mathrm{C}$-stretching was observed at $1662.1 \mathrm{~cm}^{-1}$, -C-H bending was observed at $802.4 \mathrm{~cm}^{-1}$, the $-\mathrm{C}-\mathrm{H}$ stretching was observed at $2893.1 \mathrm{~cm}^{-1}$ and the $-\mathrm{CH}_{3}$ vibrations was observed at $1442.5 \mathrm{~cm}^{-1}$ (Figure 16).
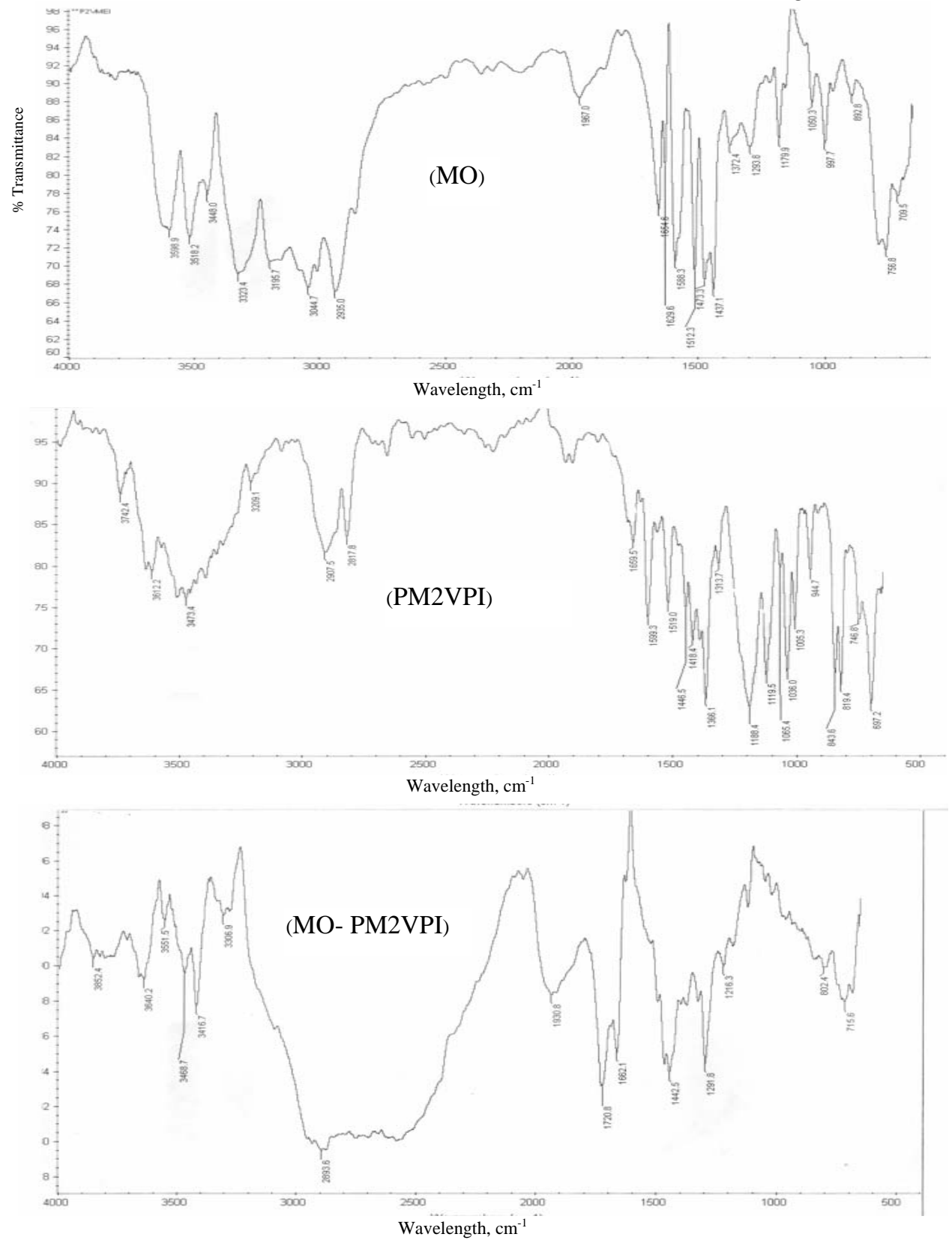

Figure 16. IR spectra of MO, PM2VPI and MO- PM2VPI complex 


\section{Conclusion}

The polymers poly( $N$-methyl-4-vinylpyridinium iodide), poly(vinyl benzyltriphenylphosphonium chloride) and poly ( $N$-methyl-2-vinylpyridinium iodide) induced metachromasy in the dye MO. The monomeric band occurs at $464 \mathrm{~nm}$ while the metachromatic band occurred at $378 \mathrm{~nm}$ in the case of MO-PM2VPI and at $426 \mathrm{~nm}$ in the case of MO- PVBTPPC and $387 \mathrm{~nm}$ in case of MO-PM2VPI. The spectral shifts are found in the order MO- PM4VPI (86 nm), MO- PM2VPI (77 nm), MO- PVBTPPC (38 nm) indicates that binding is in the order MOPM4VPI> MO-PM2VPI > MO-PVBTPPC. These results are further confirmed by the reversal studies using alcohols, urea, sodium chloride and surfactants. The thermodynamic parameters further confirm the above fact. It is thus evident from the above studies that both electrostatic and non-ionic forces contribute towards the binding process. Cooperativity in binding is observed to occur due to neighbor interactions among the bound dye molecules at lower P/D ratios leading to stacking. The stacking tendency is enhanced by the easy availability and close proximity of the charged sites.

\section{References}

1. Yamabe S, The Japanese Journal of Pharmacology, 1966, 16, 438.

2. Quadrifoglio F, Crescenzi V and Kuroki N, J Colloid Interface Sci., 1971, 35, 447.

3. Takagishi T and Kuroki N, J Polym Sci Polym Chem Ed., 1973, 11, 1889.

4. Takagishi T, Nakagami K, Imajo K and Kuroki N, J Polym Sci Polym Chem Ed., 1976, 14, 923-929.

5. Takagishi T, Kozuka H, Ju Kim G and Kuroki N, J Polym Sci Polym Chem Ed., 1981, 19, 3237.

6. Takagishi T, Kozuka H, JuKim G, Kuroki N, J Polym Sci Polym Chem Ed., 1982,20, 2231.

7. Izumi T and Hirata M, Colloid Polym Sci., 1986, 264, 756-763.

8. $\quad$ Seo T, Hagura S, Kanbara T and Iijima T, J Appl Polym Sci., 1989, 37(10), 3011-3027.

9. Hochberg G C, Colloid Polym Sci., 1994, 272, 409-415.

10. Mitra A and Chakraborty A K, Indian J Biochem Biophys., 1992, 29(3), 291-295.

11. Basu S, Gupta A K and Rohatgi-Mukherjee K K, J Indian Chem Soc., 1982, 59, 578.

12. Pal M K and Schubert M, J Histochem Cytochem., 1961, 9, 673.

13. Pal M K and Ghosh B K, Macromol Chem., 1980, 181, 1459.

14. Pal M K and Ghosh B K, Macromol Chem., 1979, 180, 959.

15. Pal M K and Schubert M, J Phys Chem., 1963, 67, 182.

16. Frank H S and Evans M W, J Chem Phys., 1945, 13, 307-314.

17. Kauzmann W, Advan Protein Chem., 1959, 14, 1-63.

18. Bruning W and Holtzer A, J Am Chem Soc., 1961, 83, 4865.

19. Whitney P L and Tanford C, J Biol Chem., 1962, 237, 1735-1737.

20. Mukerjee P and Ray A, J Phys Chem 1963, 67, 190.

21. Frank H S and Quist A S, J Chem Phys., 1961, 34, 604.

22. Rabinowitch E and Epstein L F, J Am Chem Soc., 1941, 63, 69.

23. Tan J S and Schneider R L, J Phys Chem., 1975, 79(14), 1380.

24. Romani A P, Gehlen M H and Itri R, Langmuir, 2005, 21, 127.

25. Levine A and Schubert M, J Am Chem Soc., 1958, 74, 5702.

26. Konradi R and Ruhe J, Macromolecules, 2005, 38, 6140.

27. Dasgupta S, Nath R K, Biswas S, Hossain J, Mitra A and Panda A K, Colloids Surf A: Physicochem Engg Asp., 2007, 302, 17.

28. Rose N J and Drago R S, J Am Chem Soc., 1959, 81, 6138. 


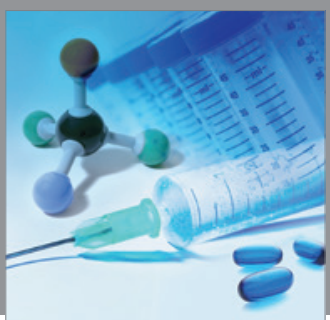

International Journal of

Medicinal Chemistry

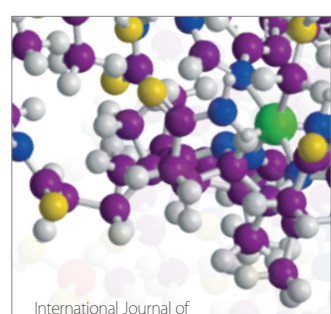

Carbohydrate Chemistry

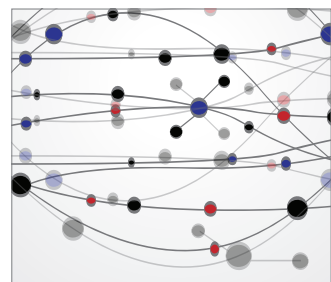

The Scientific World Journal
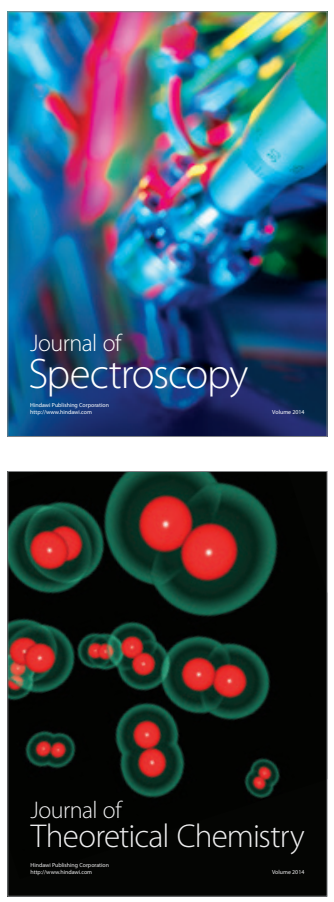
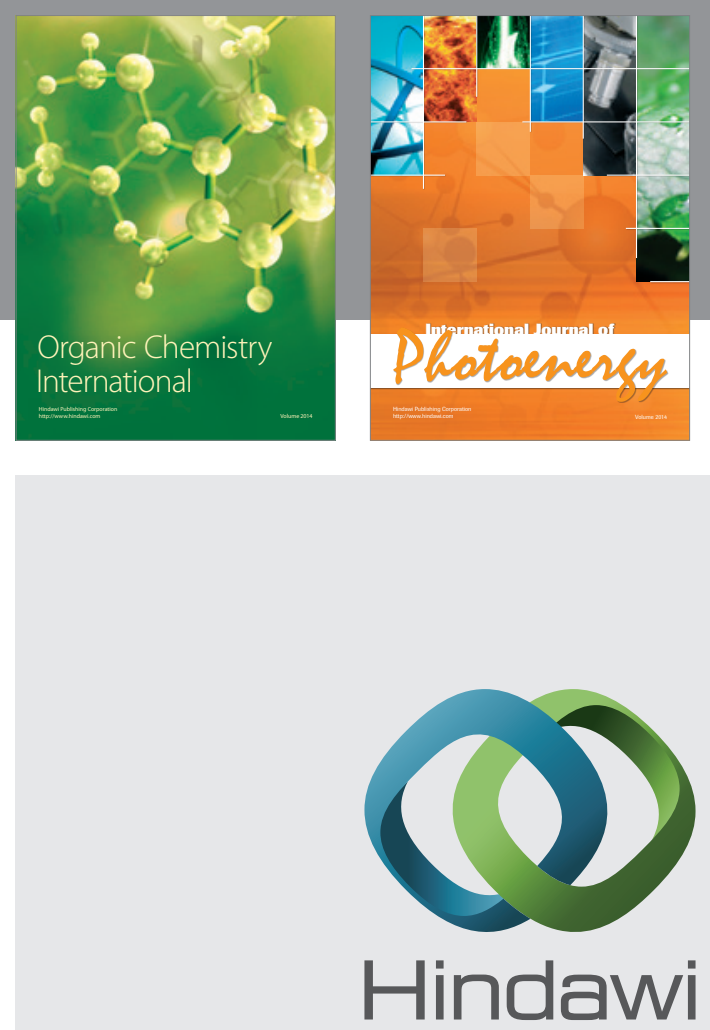

Submit your manuscripts at

http://www.hindawi.com
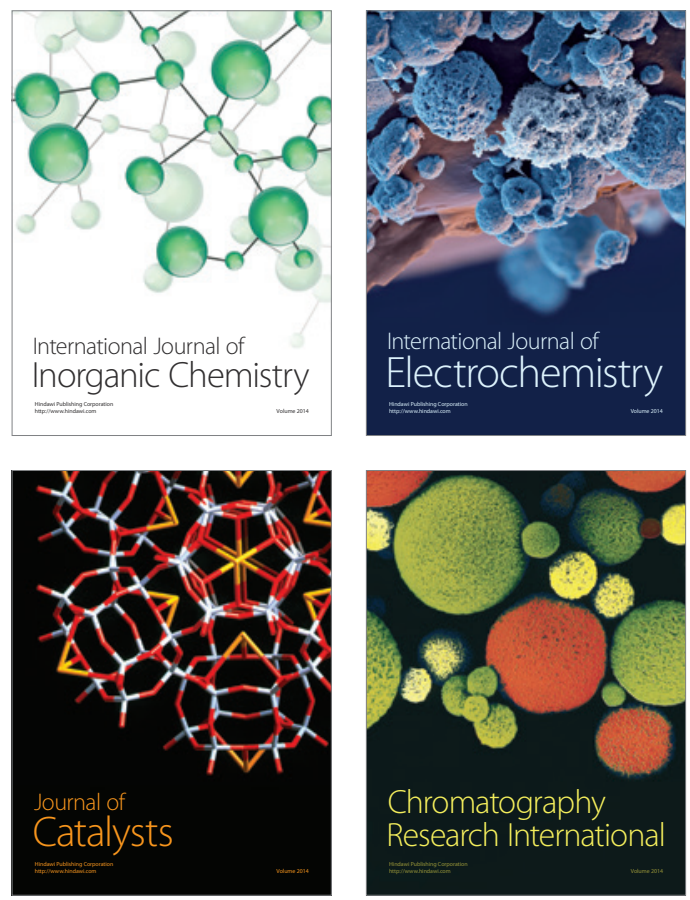
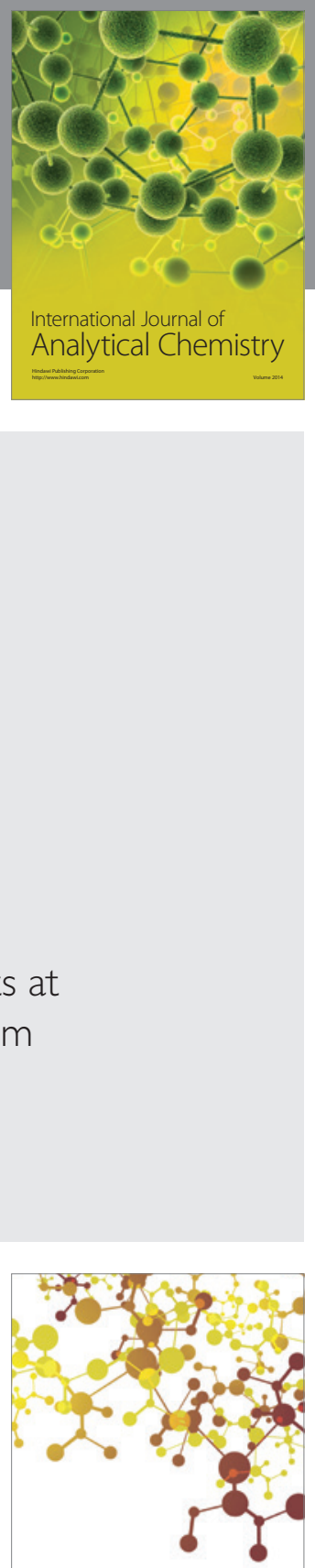

Journal of

Applied Chemistry
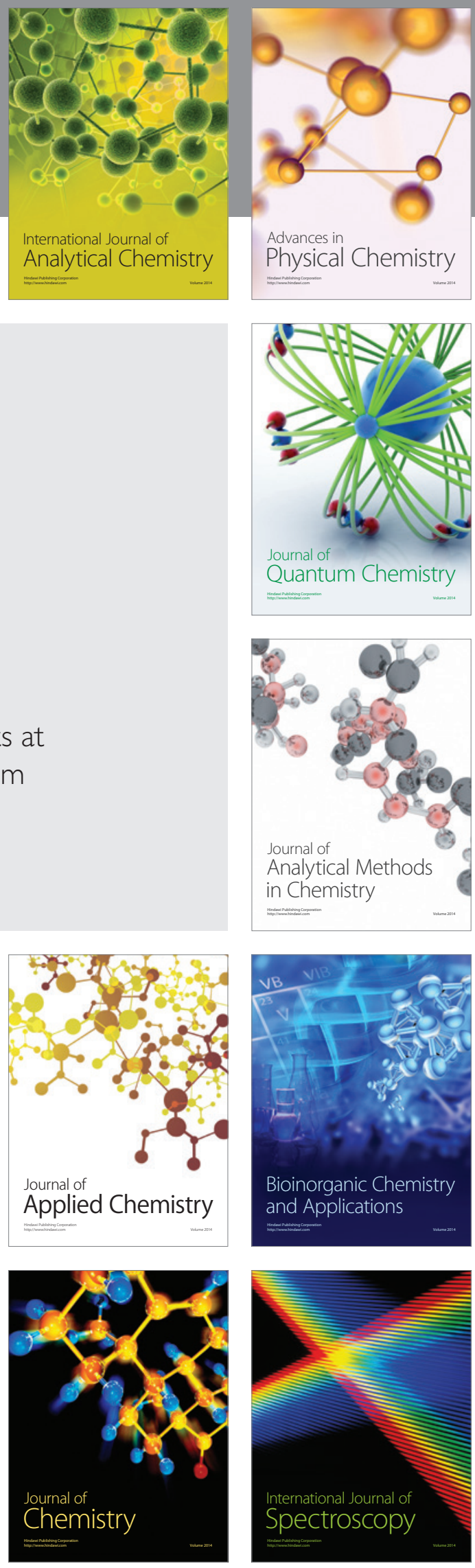